\title{
Insecticidal and Acaricidal Activity of Essential Oils Rich in $(E)$-Nerolidol from Melaleuca leucadendra Occurring in the State of Pernambuco (Brazil) and Effects on Two Important Agricultural Pests
}

\author{
Milena M. C. da Silva, ${ }^{a}$ Claudio A. G. da Camara, ${ }^{\circledR} * a, b$ Marcilio M. de Moraes, ${ }^{a}$ \\ João P. R. de Melo, ${ }^{b}$ Rodrigo B. dos Santos ${ }^{a}$ and Roberta C. S. Neves ${ }^{\oplus a}$ \\ ${ }^{a}$ Departamento de Química, Universidade Federal Rural de Pernambuco, \\ Rua Dom Manoel de Medeiros s/n, 52171-030 Recife-PE, Brazil \\ ${ }^{b}$ Departamento de Agronomia, Universidade Federal Rural de Pernambuco, \\ Rua Dom Manoel de Medeiros s/n, 52171-030 Recife-PE, Brazil
}

\begin{abstract}
Essential oils from the leaves, stems, flowers and fruits of Melaleuca leucadendra growing in the state of Pernambuco, Brazil, were analyzed using gas chromatography-mass spectrometry (GC-MS). The effects of the oils and their major constituent were evaluated on the agricultural pests Tetranychus urticae and Plutella xylostella in different stages of development. The analysis revealed a $M$. leucadendra chemotype rich in $(E)$-nerolidol $(81.78 \pm 0.90$ to $95.78 \pm 1.20 \%)$. P. xylostella was more susceptible to the oils and major constituent than T. urticae. The fruit oil was 1.5 -fold more toxic than the leaf oil to T. urticae eggs. (E)-Nerolidol was 5.5-fold and 4.5-fold more toxic to T. urticae adults than the leaf and fruit oils, respectively. Azamax ${ }^{\circledR}$ used as the positive control was more efficient than the oils and $(E)$-nerolidol against $T$. urticae. However, the oils and $(E)$-nerolidol were more toxic to P. xylostella than Azamax ${ }^{\circledR}$.
\end{abstract}

Keywords: Melaleuca leucadendra, essential oils, Tetranychus urticae, Plutella xylostella

\section{Introduction}

The family Myrtaceae is one of the most numerous of the Brazilian flora, with 1000 species in 23 genera widely distributed throughout the country. ${ }^{1}$ Melaleuca $\mathrm{L}$. is one of the most numerous among the genera, with approximately 100 species. ${ }^{2}$ Some of the species of this genus are grown for their essential oils, which are traditionally used in cosmetic and pharmaceutical formulations due to their aromatic and medicinal properties. ${ }^{3}$

According to Tran et al., ${ }^{4}$ the genus Melaleuca has a rich variety of species and significant phenotypic diversity in different ecosystems. Under adverse conditions, these species exhibit considerable adaptation capacity. For instance, Melaleuca leucadendra L. was introduced in parks and gardens in the city of Recife, state of Pernambuco, Brazil, ${ }^{5}$ but rapidly expanded and can currently be found on the edges of forest fragments, such as in Dois Irmãos State Park, which composes one of the largest fragments of the Atlantic Forest in urban areas in Brazil.

*e-mail: claudio_agc@hotmail.com
The production of secondary metabolites in plants is influenced by environmental conditions, water stress, herbivory and genetic variability. ${ }^{6}$ Thus, different chemotypes have been found in different plant species, such as those of the genus Melaleuca grown in Brazil, Australia and the Pacific Islands. ${ }^{7,8}$ Species of Melaleuca are well known for the production of essential oils with strong aromas and considerable economic importance. ${ }^{9}$ These oils are composed of a myriad of biologically active constituents with antimicrobial, anti-inflammatory and insecticidal/acaricidal properties. ${ }^{10}$

The two-spotted spider mite (Tetranychus urticae Koch, Acari: Tetranychidae) is a polyphagous pest that attacks tomato and cucumber crops in protected environments and on organic farms in the region of the lower-middle São Francisco Valley in the state of Pernambuco, Brazil. The diamond-back moth (Plutella xylostella) is another pest that causes serious damage to vegetable crops around the world, particularly cabbage, cauliflower and broccoli. ${ }^{11}$ Control with synthetic products is still the most widely used method to minimize the damage caused by these pests. ${ }^{12}$ However, even when employed correctly, large amounts of 
synthetic pesticides cause ecological imbalances, leading to arthropod populations that are resistant to the active ingredients. $^{13}$

As an alternative to synthetic products, essential oils are promising in the control of several arthropods due to their known biological properties, causing the death or affecting the behavior of different agricultural pests. Previous investigations report the effects of essential oils from M. leucadendra on agricultural pests, such as Tyrophagus putrescentiae, Sitotroga cerealella and Bemisia tabaci, ${ }^{10,14,15}$ as well as insects of interest to human medicine in the control of arboviruses, such as Aedes aegypti, Anopheles stephensi and Culex quinquefasciatus. ${ }^{16}$ However, few studies have reported the concomitant effect of extracts and/or essential oils on different stages of development of the pests investigated herein.

Giving continuity to the chemical and biological study of aromatic plants that occur in northeast Brazil, this work presents an unusual chemotype for M. leucadendra grown in the city of Recife (state of Pernambuco) with potential for the production of essential oils rich in $(E)$-nerolidol. The insecticidal and acaricidal effects of the essential oils from M. leucadendra and their major constituent on Tetranychus urticae and Plutella xylostella are presented for the first time.

\section{Experimental}

\section{General procedures}

Optical rotation was measured on a digital polarimeter (A. Krüss model Px800, Germany) operating at $589 \mathrm{~nm}$ and $25^{\circ} \mathrm{C}$ in a dichloromethane solution. Gas chromatography (GC) (500 GC, PerkinElmer Clarus, Shelton, CO, USA) was performed using an apparatus equipped with a flame ionization detector (FID) and a non-polar DB-5 fused silica capillary column $(30 \mathrm{~m} \times 0.25 \mathrm{~mm} \times 0.25 \mu \mathrm{m})$. The oven temperature was programmed from 60 to $240{ }^{\circ} \mathrm{C}$ at a rate $3{ }^{\circ} \mathrm{C} \mathrm{min}{ }^{-1}$. The injector and detector temperature was $260{ }^{\circ} \mathrm{C}$. Hydrogen was used as the carrier gas at a flow rate of $1 \mathrm{~mL} \mathrm{~min}^{-1}$ in split mode (1:30). The injection volume was $0.5 \mu \mathrm{L}$ of diluted solution (1/100) of oil in $n$-hexane. The amount of each compound was calculated from GC-FID peak areas in the order of DB-5 column elution and expressed as a relative percentage of the total area of the chromatograms. Gas chromatography-mass spectrometry (GC-MS) (Clarus ${ }^{\circledR} 580$ PerkinElmer, Shelton, CO, USA) analyses were carried out using a system with a mass selective detector, mass spectrometer in electron ionization (EI) $70 \mathrm{eV}$ with a scan interval of $0.5 \mathrm{~s}$ and fragments from 40 to $550 \mathrm{Da}$ fitted with the same column and temperature program as that for the GC-FID analyses, with the following parameters: carrier gas = helium; flow rate $=1 \mathrm{~mL} \mathrm{~min}^{-1} ;$ split mode $(1: 30)$; injected volume $=1 \mu \mathrm{L}$ of diluted solution (1/100) of oil in $n$-hexane. Infrared (IR) spectra were measured in $\mathrm{KBr}$ pellets in a PerkinElmer model 1750 infrared spectrophotometer. ${ }^{1} \mathrm{H}$ and ${ }^{13} \mathrm{C}$ nuclear magnetic resonance (NMR) spectra were recorded at 300 and $75 \mathrm{MHz}$, respectively, in a Bruker DPX-300 (Bruker BioSpin GmbH, Silberstreifen, Rheinstetten, Germany) using $\mathrm{CDCl}_{3}$ (Aldrich, St. Louis, MO, USA) as solvent and tetramethylsilane (TMS) as reference. Chemical shifts are reported in d units (ppm) and coupling constants $(J)$ in Hz. Silica gel (Macherey-Nagel, 70-230 mesh) was used for column chromatographic separations, while silica gel 60G (Acros Organic) was used for analytical thin layer chromatography (TLC).

\section{Chemicals}

All monoterpenes $(\alpha$-pinene $(\geq 99 \%), \beta$-pinene $(\geq 99 \%)$, limonene $(\geq 97 \%), 1,8$-cineole $(=97 \%)$, terpinen-4-ol $(\geq 95 \%)$ and $\alpha$-terpineol $(\geq 90 \%))$ and sesquiterpenes ( $\beta$-caryophyllene $(\geq 98 \%),(E)$-nerolidol $(\geq 98 \%)$ and spathulenol $(\geq 97 \%)$ ) used in the identification of volatile components were purchased from SigmaAldrich, Brazil, with high purity analytical standards. Azamax $^{\circledR} 12$ g i.a./L EC E.I.D. Parry (azadirachtin) used as positive control was purchased in the local market.

\section{Collection of plant material}

Fresh leaves, stems, flowers and fruits of Melaleuca leucadendra L. were collected from a fragment of the Atlantic forest in the city of Recife, state of Pernambuco, Brazil, in June 2018. The plants were identified by Dr Maria Rita Cabral Sales de Melo of the Biology Department of the Universidade Federal Rural de Pernambuco (UFRPE). A voucher specimen was deposited in the UFRPE herbarium under No. 48.489.

\section{Essential oil extraction}

Essential oils from fresh parts of the plant (100 g) were obtained through hydrodistillation for $2 \mathrm{~h}$ using a modified Clevenger-type apparatus. The oil layers were separated and dried over anhydrous sodium sulfate, stored in hermetically sealed glass containers, and kept at low temperature $\left(-5^{\circ} \mathrm{C}\right)$ until analysis. Total oil yields were expressed as percentages ( $\left(\mathrm{g} 100 \mathrm{~g} \mathrm{~g}^{-1}\right.$ of fresh plant material). All experiments were carried out in triplicate. 
Identification of essential oil components

Identification of the components was based on GC-MS retention indices with reference to a homologous series of $\mathrm{C}_{8}-\mathrm{C}_{40} n$-alkanes calculated using the Van den Dool and Kratz equation ${ }^{17}$ and by computer matching against the mass spectral library of the GC-MS data system (NIST 14 and WILEY $11^{\text {th }}$ ) and co-injection with authentic standards as well as other published mass spectra. ${ }^{18}$ Area percentages were obtained from the GC-FID response without the use of an internal standard or correction factors.

\section{Acquisition and rearing of Tetranychus urticae}

Tetranychus urticae (Acari: Tetranychidae) adults were originally collected from grapevine (Vitis vinifera L.) (June 2016) in the municipality of Petrolina, PE (09²12'43.9''S; $40^{\circ} 29^{\prime} 12.7^{\prime \prime} \mathrm{W}$ ), and were maintained in the laboratory at the Agronomy Department of the Universidade Federal Rural de Pernambuco, Brazil, since June 2017. Individuals were reared at a temperature of $25 \pm 1^{\circ} \mathrm{C}$, relative humidity of $65 \pm 5 \%$ and a 12 -h photoperiod without any exposure to acaricides. T. urticae used for the bioassays was reared on jack bean (Canavalia ensiformes L.). The breeding method was adapted from Ribeiro et al. ${ }^{19}$

\section{Acquisition and rearing of Plutella xylostella}

Adult, pupae, larvae and eggs of Plutella xylostella (L.) (Lepidoptera: Plutellidae) were originally collected from cabbage (Brassica oleracea var. acephala) in the municipality of Recife, PE (0801'08.3'S 3456'45.5”W) and maintained since then in the laboratory at the Agronomy Department of the Universidade Federal Rural de Pernambuco, Brazil. Individuals were reared at a temperature of $25 \pm 1{ }^{\circ} \mathrm{C}$, relative humidity of $65 \pm 5 \%$ and a 12-h photoperiod without any exposure to insecticides. P. xylostella used for the bioassays was reared on cabbage (Brassica oleracea var. acephala). The breeding method was adapted from Bandeira et al..$^{20}$

\section{Acaracidal assay with T. urticae}

The residual effect bioassays were based on the method described by Moraes et al. ${ }^{21}$ with modifications. Leaf discs (2.5 cm diameter) were cut from leaves of greenhousegrown jack bean. A $20-\mu \mathrm{L}$ aliquot of each concentration was painted on the underside of the disc with a micropipette. Each disc was individually placed in the bottom of a Petri dish (10 cm diameter) atop a disc of filter paper wetted with Milli-Q water. Ten adult female mites were placed on each leaf disc. To observe the action of the oils and compounds tested, all experiments were performed with open Petri dishes. The concentrations of Melaleuca leucadendra oils ranged from 2.0 to $18.5 \mu \mathrm{L} \mathrm{mL}^{-1}$. The concentrations of $(E)$-nerolidol ranged from 0.5 to $4.80 \mu \mathrm{L} \mathrm{mL}^{-1}$. The concentrations of the positive control (Azamax ${ }^{\circledR}$ ) ranged from 0.04 to $100 \mu \mathrm{L} \mathrm{mL}^{-1}$. The oils, major constituent and positive control were dissolved in an aqueous solution (1.0\% polyoxyethylene sorbitan monolaurate $+0.1 \%$ dodecylbenzene sulfonic acid). Negative control discs were sulfonic immersed in the aqueous solution alone. Mortality was determined under a dissecting microscope $24 \mathrm{~h}$ after treatment. All the mites were considered dead if appendages did not move when prodded with a fine paintbrush. All treatments were replicated tree times.

\section{Ovicidal assay with T. urticae}

The method used to determine the ovicidal effects of the essential oils on T. urticae eggs was the same as that employed by Salman et al..$^{22}$ Leaf discs $(2.5 \mathrm{~cm}$ in diameter) of $C$. ensiformes were placed in Petri dishes $(10 \mathrm{~cm}$ in diameter) containing filter paper discs on sponge saturated in Milli-Q water to maintain the turgidity of the leaves. Ten adult $T$. urticae females were transferred to each leaf disc for the obtainment of the eggs. After $15 \mathrm{~h}$, the females were removed and the eggs were counted; only 30 eggs were used per leaf disc. The experiments were performed in triplicate, totaling 270 T. urticae eggs for each concentration tested. After the egg counts, the concentrations of the oils, major constituent and positive control were dissolved in an aqueous solution (1.0\% polyoxyethylene sorbitan monolaurate $+0.1 \%$ dodecylbenzene sulfonic acid) and applied using the immersion method. The concentrations of the Melaleuca leucadendra oils ranged from 0.05 to $0.40 \mu \mathrm{L} \mathrm{mL}^{-1}$. The concentrations of $(E)$-nerolidol ranged from 0.20 to $130 \mu \mathrm{L} \mathrm{mL}^{-1}$. The concentrations of the positive control $\left(\right.$ Azamax $^{\circledR}$ ) ranged from 50 to $300 \mu \mathrm{L} \mathrm{mL}^{-1}$. Negative control discs were immersed in the aqueous solution alone. After drying at room temperature for $30 \mathrm{~min}$, the leaf discs containing the eggs were placed on filter paper on sponge saturated with water in plastic trays and kept in a climatic chamber (BOD MA 403) at $25 \pm 1{ }^{\circ} \mathrm{C}$ and $70 \pm 10 \%$ relative humidity. Egg viability was evaluated 96 h after exposure to the oils, compound and positive control through counts of the number of hatched larvae.

\section{Larvicidal assay with $P$. xylostella}

The residual effect bioassays were based on the method described by Moraes et al., ${ }^{21}$ with modifications. 
The experiments were performed with open Petri dishes (10 $\mathrm{cm}$ diameter). Leaf discs $(2.5 \mathrm{~cm}$ diameter $) \mathrm{cut}$ from cabbage were immersed for $30 \mathrm{~s}$ in the solutions prepared with essential oil or blends of oils or individual chemical constituents, diluted in the aqueous solution and allowed to dry on a paper towel at room temperature for $1 \mathrm{~min}$. The concentrations of Melaleuca leucadendra oils ranged from 0.05 to $0.35 \mu \mathrm{L} \mathrm{mL} \mathrm{m}^{-1}$. The concentrations of $(E)$-nerolidol ranged from 0.05 to $0.30 \mu \mathrm{L} \mathrm{mL}^{-1}$. The concentrations of positive control $\left(\right.$ Azamax $\left.^{\oplus}\right)$ ranged from 50 to $350 \mu \mathrm{L} \mathrm{mL}^{-1}$. Negative control discs were only immersed in $1.0 \%$ polyoxyethylene sorbitan monolaurate $+0.1 \%$ dodecylbenzene sulfonic acid. After drying, the discs were transferred to Petri dishes containing filter paper slightly moistened with distilled water. Thirty instar P. xylostella larvae were placed in each dish. Mortality was recorded after $48 \mathrm{~h}$ of exposure. The experimental design was entirely randomized, with four repetitions, totaling 120 larvae per treatment.

\section{Ovicidal assay with $P$. xylostella}

The method used to determine the ovicidal effects of the essential oils, compound and positive control on P. xylostella eggs was the same as that employed by Zago et al. ${ }^{23}$ Ten recently emerged mating pairs of $P$. xylostella were placed in screened recipients containing leaf discs $(2.5 \mathrm{~cm}$ in diameter) of cabbage for oviposition. The leaf discs were in Petri dishes (10 $\mathrm{cm}$ in diameter) containing filter paper on sponge saturated with Milli-Q water to maintain the turgidity of the leaves. The leaf discs were replaced twice a day at an interval of one to six hours. The eggs on each leaf disc were counted, maintaining 30 eggs per disc. After the egg counts, the concentrations of the oils, major constituent and positive control were dissolved in an aqueous solution (1.0\% polyoxyethylene sorbitan monolaurate $+0.1 \%$ dodecylbenzene sulfonic acid) and applied using the immersion method. The experiments were performed in triplicate, totaling 120 P. xylostella eggs per concentration. The concentrations of the Melaleuca leucadendra oils ranged from 0.05 to $0.40 \mu \mathrm{L} \mathrm{mL}^{-1}$. The concentrations of $(E)$-nerolidol ranged from 0.20 to $130 \mu \mathrm{L} \mathrm{mL}^{-1}$. The concentrations of the positive control $\left(\right.$ Azamax $\left.^{\circledR}\right)$ ranged from 50 to $300 \mu \mathrm{L} \mathrm{mL}^{-1}$. Negative control discs were immersed in the aqueous solution alone. After drying at room temperature for $30 \mathrm{~min}$, leaf discs containing eggs were placed on filter paper on sponge saturated with water in plastic trays and kept in a climatic chamber (BOD MA 403) at $25 \pm 1{ }^{\circ} \mathrm{C}$ and $70 \pm 10 \%$ relative humidity. Egg viability was evaluated $72 \mathrm{~h}$ after exposure to the oils, compound and positive control through counts of the number of hatched larvae.

\section{Statistical analysis}

To estimate the curve slopes and lethal concentration $\left(\mathrm{LC}_{50}\right)$, mortality data from the residual contact and ovicidal assays of each Melaleuca leucadendra oil (leaves and fruits), compound (E)-nerolidol and positive control $\left(\right.$ Azamax $^{\circledR}$ ) were submitted to PROBIT analysis ${ }^{24}$ using the SAS software (version 9.0). ${ }^{25}$

\section{Results and Discussion}

\section{Chemical composition}

The essential oils from the leaves, stems, flowers and fruits of Melaleuca leucadendra obtained through hydrodistillation had a yellow color and citric aroma. The greatest yield was achieved with the leaf oil $(0.28 \pm 0.05 \%)$. The analysis of the chemical composition of the oils by GC-MS enabled the identification of 16 compounds, corresponding to $97.54 \pm 1.35 \%$, $98.04 \pm 1.24 \%, 97.97 \pm 0.95 \%$ and $95.15 \pm 0.48 \%$ of the leaf, stem, flower and fruit oils, respectively. The oils had a terpene chemical profile, with a predominance of sesquiterpenes (Table 1).

(E)-Nerolidol was the major constituent of the M. leucadendra oils, accounting for $94.27 \pm 1.32 \%$, $95.78 \pm 1.20 \%, 81.78 \pm 0.90 \%$ and $92.06 \pm 0.45 \%$ of the leaf, stem, flower and fruit oils, respectively. The chemical structure of the dominant compound ( $E$ )-nerolidol) was identified from the mass fragmentation pattern and retention index (RI) values were obtained. The compound was also purified and its identification was further confirmed by the GC-MS, IR, NMR ${ }^{1} \mathrm{H}$ and ${ }^{13} \mathrm{C}$ data (Supplementary Information section).

The results are in agreement with data reported by Padalia et al. ${ }^{9}$ for a specimen of $M$. leucadendra collected in India, which also had $(E)$-nerolidol as the major constituent in the leaf $(90.85 \%)$, stem (86.13\%) and flower (76.58\%) oils. This oxygenated sesquiterpene was also found as the major constituent of M. leucadendra leaf oil (37.3\%) collected in Benin ${ }^{26}$ and Venezuela (28.7\%). ${ }^{27}$

In contrast, other chemotypes have been found for M. leucadredra collected in different parts of Brazil and the world. For instance, 1,8-cineole (22.45 to $60.19 \%$ ) was found as the major constituent of the leaf oil from samples collected in Indonesia, ${ }^{28-30} \operatorname{Egypt}(64.3 \%),{ }^{31} \operatorname{India}(19.9 \%),{ }^{32}$ Cuba (43.0\%), ${ }^{33}$ Vietnam (48.0\%), ${ }^{34}$ Ivory Coast (50.4 to $48.5 \%)^{15}$ and Venezuela (38.4\%). ${ }^{27}$ Moreover, $\gamma$-terpinene (24.5 to $5.44 \%), \alpha$-terpinolene (22.79 to $6.39 \%$ ) and $\beta$-caryophyllene ( 27.4 to $3.32 \%$ ) were identified as major constituents in $M$. leucadendra collected in different 
Table 1. Percentage composition, yield of essential oils of leaves, stems, flowers and fruits from Melaleuca leucadendra

\begin{tabular}{|c|c|c|c|c|c|c|c|}
\hline Compound & $\mathrm{RI}^{\mathrm{a}}$ & $\mathrm{RI}^{\mathrm{b}}$ & Leaves & Stems & Flowers & Fruits & $\begin{array}{l}\text { Method of } \\
\text { identification }\end{array}$ \\
\hline Yield $\pm \mathrm{SD} / \%$ & & & $0.28 \pm 0.05$ & $0.02 \pm 0.00$ & $0.03 \pm 0.01$ & $0.18 \pm 0.03$ & \\
\hline$\alpha$-Pinene & 930 & 932 & $0.10 \pm 0.01$ & $0.12 \pm 0.01$ & $1.79 \pm 0.10$ & - & RI, MS, CI \\
\hline$\beta$-Pinene & 966 & 961 & $0.12 \pm 0.02$ & $0.01 \pm 0.00$ & $2.72 \pm 0.13$ & $0.03 \pm 0.00$ & RI, MS, CI \\
\hline Limonene & 1021 & 1025 & $0.28 \pm 0.07$ & - & $0.01 \pm 0.00$ & - & RI, MS, CI \\
\hline 1,8-Cineole & 1025 & 1026 & $1.44 \pm 0.16$ & $0.24 \pm 0.03$ & $1.10 \pm 0.14$ & $0.44 \pm 0.04$ & RI, MS, CI \\
\hline Terpinen-4-ol & 1177 & 1174 & $0.27 \pm 0.03$ & - & $0.11 \pm 0.01$ & - & RI, MS, CI \\
\hline$\alpha$-Terpineol & 1187 & 1186 & $0.28 \pm 0.01$ & - & $0.77 \pm 0.06$ & $0.05 \pm 0.01$ & RI, MS, CI \\
\hline$\beta$-Caryophyllene & 1420 & 1417 & $0.37 \pm 0.02$ & $0.34 \pm 0.02$ & $1.64 \pm 0.07$ & - & RI, MS, CI \\
\hline (Z)- $\beta$-Farnesene & 1441 & 1440 & $0.06 \pm 0.00$ & - & $0.42 \pm 0.02$ & $0.11 \pm 0.01$ & RI, MS \\
\hline$\alpha$-Patchoulene & 1457 & 1454 & $0.03 \pm 0.00$ & - & $0.71 \pm 0.04$ & - & RI, MS \\
\hline$(E)$-Nerolidol & 1566 & 1561 & $94.27 \pm 1.32$ & $95.78 \pm 1.20$ & $81.78 \pm 0.90$ & $92.06 \pm 0.45$ & RI, MS, CI \\
\hline Spathulenol & 1572 & 1577 & $0.14 \pm 0.00$ & $0.20 \pm 0.01$ & $3.83 \pm 0.21$ & $0.28 \pm 0.01$ & RI, MS, CI \\
\hline Viridiflorol & 1594 & 1592 & $0.05 \pm 0.00$ & - & $0.39 \pm 0.02$ & - & RI, MS \\
\hline Allo-aromadendrene & 1641 & 1639 & - & - & $0.56 \pm 0.07$ & $0.03 \pm 0.00$ & RI, MS, CI \\
\hline$\alpha$-Eudesmol & 1655 & 1652 & $0.01 \pm 0.00$ & $0.11 \pm 0.01$ & $0.56 \pm 0.10$ & - & RI, MS \\
\hline Intermediol & 1670 & 1665 & - & $0.01 \pm 0.00$ & $0.30 \pm 0.02$ & $0.15 \pm 0.02$ & RI, MS \\
\hline epi- $\alpha$-Bisabolol & 1686 & 1683 & $0.12 \pm 0.01$ & $1.23 \pm 0.08$ & $2.22 \pm 0.13$ & $2.00 \pm 0.09$ & RI, MS \\
\hline Total & & & $97.54 \pm 1.35$ & $98.04 \pm 1.24$ & $97.97 \pm 0.95$ & $95.15 \pm 0.48$ & \\
\hline Monoterpenes & & & $2.49 \pm 0.14$ & $0.37 \pm 0.03$ & $5.56 \pm 0.10$ & $0.52 \pm 0.04$ & \\
\hline Sesquiterpenes & & & $95.05 \pm 1.27$ & $97.67 \pm 1.20$ & $92.41 \pm 0.95$ & $94.63 \pm 0.046$ & \\
\hline
\end{tabular}

aRI: retention indices calculated from retention times in relation to those of a $\mathrm{C}_{8}$ - $\mathrm{C}_{40}$ series of $n$-alkanes on a $30 \mathrm{~m}$ DB- 5 capillary column; ${ }^{\mathrm{R} I}$ : retention indices from the literature. SD: standard deviation; RI: retention index; MS: mass spectroscopy; CI: co-injection with authentic compounds.

regions of Indonesia ${ }^{35}$ and terpinen-4-ol (36.85\%) was identified as the major constituent in the leaf oil of a sample collected in China. ${ }^{36}$

Another chemotype belonging to the class of phenylpropanoids has been reported for M. leucadendra. The leaf oil from plants collected in two locations in Australia exhibited methyl eugenol (97.40\%) and (E)-methyl-isoeugenol $(88.80 \%)$ as the major constituents. ${ }^{7}$ The methyl eugenol chemotype has also been reported in the state of Minas Gerais, Brazil $(96.6 \pm 0.7 \%)^{8}$ and Pakistan (95.4\%). ${ }^{37}$ The occurrence of different chemotypes for aromatic species may stem from genetic variability and the influence of the environment, suggesting the rapid evolution of this species in different ecosystems. ${ }^{38,39}$

Insecticidal and acaricidal activity

Due to the low yields of the stem and flower oils, only the leaf and fruit oils of $M$. leucadendra were evaluated with regards to toxicity to different development stages of Plutella xylostella and Tetranychus urticae. Table 2 displays the estimated mean lethal concentrations $\left(\mathrm{LC}_{50}\right)$ for the
M. leucadendra oils against $P$. xylostella and T. urticae in the residual contact and ovicidal bioassays.

The M. leucadendra leaf and fruit oils were toxic to the agricultural pests investigated herein. Some essential oils from different plants are known to have acaricidal and insecticidal activity against different development stages of T. urticae and P. xylostella. ${ }^{19,21,22,40,41}$ However, this is the first report of the acaricidal/insecticidal action of the leaf and fruit oils from M. leucadendra against these pests.

Based on the $\mathrm{LC}_{50}$ estimates for the oils tested against P. xylostella larvae and eggs, significant differences were found in the susceptibility of these two development stages of the pest, but no significant differences were found between the oils (Table 2). The larval development stage was more susceptible to the oils than the egg stage. These results are similar to findings described by Verkerk and Wright ${ }^{42}$ for P. xylostella, in which the larval stage was more susceptible than the egg stage when exposed to an extract of Azadirachta indica enriched with $30 \mathrm{mg}$ of azadirachtin $\mathrm{mL}^{-1}$. In contrast, Sangha et al..$^{40}$ found greater susceptibility of the egg stage than the larval 
Table 2. Contact residual and ovicidal activity of essential oils from leaves and fruits of Melaleuca leucadendra, $(E)$-nerolidol and Azamax ${ }^{\circledR}$ against Plutella xylostella and Tetranychus urticae

\begin{tabular}{|c|c|c|c|c|c|c|}
\hline Essential oil & Bioassay & $\mathrm{N}$ & DF & Slope \pm SE & $\begin{array}{c}\mathrm{LC}_{50}(\mathrm{CI} 95 \%) / \\
\left.(\mu \mathrm{L} \mathrm{mL})^{-1}\right)\end{array}$ & $\chi^{2}$ \\
\hline \multicolumn{7}{|c|}{ Plutella xylostella } \\
\hline \multirow{2}{*}{ Leaves } & larvicidal & 840 & 5 & $1.91 \pm 0.11$ & $0.17(0.15-0.19)$ & 6.42 \\
\hline & ovicidal & 1050 & 5 & $1.87 \pm 0.09$ & $0.23(0.21-0.26)$ & 2.15 \\
\hline \multirow{2}{*}{ Fruits } & larvicidal & 730 & 5 & $1.95 \pm 0.12$ & $0.15(0.13-0.17)$ & 5.32 \\
\hline & ovicidal & 1050 & 5 & $1.78 \pm 0.09$ & $0.28(0.25-0.32)$ & 8.36 \\
\hline \multirow{2}{*}{ (E)-Nerolidol } & larvicidal & 840 & 5 & $2.10 \pm 0.11$ & $0.18(0.16-0.20)$ & 2.41 \\
\hline & ovicidal & 1050 & 5 & $2.38 \pm 0.13$ & $0.66(0.59-0.73)$ & 7.16 \\
\hline \multirow{2}{*}{ Azamax } & larvicidal & 840 & 5 & $1.55 \pm 0.09$ & $2.75(2.37-3.19)$ & 3.51 \\
\hline & ovicidal & 1050 & 5 & $1.92 \pm 0.10$ & $2.57(2.29-2.86)$ & 3.90 \\
\hline \multicolumn{7}{|c|}{ Tetranychus urticae } \\
\hline \multirow{2}{*}{ Leaves } & adulticidal & 630 & 5 & $4.63 \pm 0.15$ & $11.53(9.89-12.08)$ & 2.03 \\
\hline & ovicidal & 1890 & 5 & $1.54 \pm 0.10$ & $1.19(0.98-1.41)$ & 8.81 \\
\hline \multirow{2}{*}{ Fruits } & adulticidal & 630 & 5 & $2.27 \pm 0.19$ & $9.52(8.97-10.03)$ & 4.45 \\
\hline & ovicidal & 1890 & 5 & $1.57 \pm 0.15$ & $0.73(0.61-0.84)$ & 5.62 \\
\hline \multirow{2}{*}{ (E)-Nerolidol } & adulticidal & 540 & 4 & $1.89 \pm 0.19$ & $2.09(1.69-2.59)$ & 0.38 \\
\hline & ovicidal & 1850 & 3 & $1.35 \pm 0.11$ & $0.50(0.35-0.69)$ & 7.19 \\
\hline \multirow{2}{*}{ Azamax } & adulticidal & 630 & 5 & $2.45 \pm 0.16$ & $0.30(0.27-0.36)$ & 8.30 \\
\hline & ovicidal & 1890 & 5 & $0.60 \pm 0.06$ & $0.003(0.002-0.004)$ & 5.09 \\
\hline
\end{tabular}

$\mathrm{N}$ : number of larvae; DF: degrees of freedom; SE: standard error of mean; $\chi^{2}$ : chi-squared test ( $\left.p>0.05\right)$; CI: confidence interval.

stage of P. xylostella when exposed to different essential oils, especially the Alium sativum oil.

In the bioassays with $T$. urticae adults and eggs, no significant difference was found in the level of toxicity of the fruit and leaf oils to the adult stage of the pest. However, the fruit oil was 1.5 -fold more toxic to the T. urticae eggs than the leaf oil. Contrary to what was found for P. xylostella, in which the larval development stage was more susceptible than the egg stage, the egg stage of the two-spotted spider mite was 9.7-fold and 13.0-fold more susceptible than the adult stage when exposed to the leaf and fruit oils, respectively. Salman et al..$^{22}$ found similar results investigating the adulticidal and ovicidal properties of four essential oils against T. urticae, with the egg stage more susceptible than the adult stage when exposed to the oil from Hyssopus officinalis. However, the authors found contrary results for the oils from Salvia officinalis and Rosmarinus officinalis, which were more toxic to the adult stage than the egg stage of the mite.

The chemical profiles characterized for the oils evaluated with regards to their action against different development stages of P. xylostella and T. urticae were very similar, with small qualitative and quantitative differences in their constituents (Table 1). However, this small difference in chemical composition is observed in the different levels of toxicity between the oils when exposed to the mite in the egg stage, but not the larval or egg stages of P. xylostella.

In this study, a chemotype rich in $(E)$-nerolidol is reported for M. leucadendra occurring in a fragment of the Atlantic Forest biome in the state of Pernambuco (northeast Brazil), with proportions higher than $92 \%$ in the leaf and fruit oils. To assess the role of this major constituent of the oils investigated, $(E)$-nerolidol was isolated for the evaluation of its insecticidal and acaricidal action, which varied depending on the development stage of the pests. While $(E)$-nerolidol was 4.2 -fold more toxic to the egg stage than the adult stage of $T$. urticae, this sesquiterpene was 3.7 -fold more toxic to the larval stage than the egg stage of $P$. xylostella.

The toxicity found for $(E)$-nerolidol to P. xylostella larvae was the same as that found for the leaf and fruit oils, whereas its ovicidal action was lower than that of the oils. For T. urticae, $(E)$-nerolidol was 5.5-fold and 4.5-fold more toxic to adult forms than the leaf and fruit oils, respectively. However, this sesquiterpene had the same level of toxicity as the fruit oil to the egg stage of the mite. T. urticae eggs were 2.4-fold more susceptible to the major constituent 
of the oils than to the leaf oil. These results (toxicity of (E)-nerolidol greater or similar to that of the oils) suggests that the major constituent plays an important role in the toxicity of the oils. However, besides the relative toxicity of $(E)$-nerolidol, its proportion in the oils and possible interactions with minor constituents should be taken into consideration. ${ }^{41}$

To gain a notion of the efficiency of the M. leucadendra oils and major constituent investigated herein against P. xylostella and T. urticae, insecticidal/acaricidal tests were performed with the plant-based commercial product $\left(\right.$ Azamax $^{\circledR}$ ) used as the positive control under the same conditions as those used for the essential oils and major constituent. Based on the $\mathrm{LC}_{50}$ estimates, the $M$. leucadendra leaf and fruit oils were respectively 16-fold and 17-fold more toxic to P. xylostella larvae than the positive control. Greater toxicity of the oils compared to Azamax ${ }^{\circledR}$ was also found regarding the action against P. xylostella eggs, with the leaf and fruit oils respectively 11-fold and 19-fold more toxic than the positive control. In contrast, the toxicity of Azamax ${ }^{\circledR}$ was much greater to T. urticae than the oils and major constituent independently of the development stage (Table 2).

Populations of $T$. urticae resistant to conventional insecticides have been reported in different parts of the world, ${ }^{43}$ including Brazil. ${ }^{44}$ Although there are no reports of T. urticae populations resistant to the natural product azadirachtin, which is the active ingredient in Azamax ${ }^{\circledR}$, Feng and Isman $^{45}$ report that populations of the green aphid (Myzus persicae Sulzer) developed resistance to this nor-triterpenoid, but not to an extract from the seeds of Azadirachta indica containing azadirachtin and other constituents. These results suggest that complex blends of chemical compounds, such as vegetal extracts and essential oils, may be more advantageous in the medium and long terms than products formulated with only a single active ingredient. ${ }^{46}$

\section{Conclusions}

Chemical analysis by GC-MS enabled the identification of a chemotype with a predominance of $(E)$-nerolidol (> 80\%) for the leaf, stem, flower and fruit oils of M. leucadendra collected from a fragment of the Atlantic Forest in the state of Pernambuco, Brazil. The M. leucadendra leaf and fruit oils are promising against Plutella xylostella and Tetranychus urticae, which are two important agricultural pests that occur in the lower-middle São Francisco Valley in the state. Between these two pests, P. xylostella was more susceptible to the oils and major constituent. The chromatographic column isolation of $(E)$-nerolidol, which is the major constituent of the M. leucadendra oils, enabled the identification of its importance to the toxicity of the leaf and fruit oils against the target pests investigated herein.

These present findings indicate that the M. leucadendra essential oils and $(E)$-nerolidol are promising natural acaricidal/insecticidal agents with more than one mode of action (larvicidal, adulticidal and ovicidal). However, further studies are needed to investigate the effect of these oils and constituent on non-target organisms and establish the cost-benefit ratio for the formulation of an acaricide/ insecticide for use in the management of P. xylostella and T. urticae in organic and protected farming activities.

\section{Supplementary Information}

The total ion chromatograms of oils are available free of charge at http://jbcs.sbq.org.br as a PDF file.

\section{Acknowledgments}

This work was supported by Fundação de Amparo à Ciência e Tecnologia do Estado de Pernambuco (FACEPE) (grant number APQ-1008-1.06/15; APQ-0476-1.06/14; APQ-08601.06/16; IBPG-0344-1.06/17); Conselho Nacional de Desenvolvimento Científico e Tecnológico (CNPq) (grant number PQ-2-302860/2016-9) and Coordenação de Aperfeiçoamento de Pessoal de Nível Superior (CAPES) (grant number PROCAD-88887.308194/2018-00).

\section{References}

1. Souza, V. C.; Lorenzi, H.; Botânica Sistemática: Guia Ilustrado para Identificação das Famílias de Angiospermas da Flora Brasileira, baseado em APG II, $2^{\text {nd }}$ ed.; Instituto Plantarum: Nova Odessa, Brazil, 2008.

2. Southwell, I.; Lowe, R.; Tea Tree: the Genus Melaleuca; CRC Press: Amsterdam, 2003.

3. Pino, J. A.; Regalado, E. L.; Rodriguez, J. L.; Fernández, M. D.; Chem. Biodiversity 2010, 7, 2281.

4. Tran, D. B.; Dargusch, P.; Moss, P.; Hoang, T. V.; Mitig. Adapt. Strat. Gl. 2013, 18, 851.

5. Lorenzi, H.; Souza, H. M.; Torres, M. A. V.; Bacher, L. B.; Árvores Exóticas no Brasil: Madeireiras, Ornamentais e Aromáticas; Instituto Plantarum: Nova Odessa, Brazil, 2003.

6. Zhao, J.; Davis, L. C.; Verpoorte, R.; Biotechnol. Adv. 2005, 23,283 .

7. Brophy, J. J.; Lassak, E. V.; Flavour Fragrance J. 1988, 3, 43.

8. Silva, C. J.; Barbosa, L. C. A.; Maltha, C. R. A.; Pinheiro, A. L.; Ismail, F. M. D.; Flavour Fragrance J. 2007, 22, 474.

9. Padalia, R. C.; Verma, R. S.; Chauhan, A.; Chanotiy, C. S.; Ind. Crops Prod. 2015, 69, 224. 
10. Song, J. E.; Kim, J. M.; Lee, N. H.; Yang, J. Y.; Lee, H. S.; J. Food Prot. 2016, 79, 174.

11. Gautam, M. P.; Singh, H.; Kumar, S.; Kumar, V.; Singh, G.; Singh, S. N.; J. Entomol. Zool. Stud. 2018, 6, 1394.

12. Sakomoto, N.; Saito, S.; Taro, H.; Suzuki, M.; Matsuo, S.; Pest Manage. Sci. 2003, 60, 25.

13. de Oliveira, A. C.; de Siqueira, H. A. A.; de Oliveira, J. V.; da Silva, J. E.; Michereff Filho, M.; Sci. Agric. 2011, 68, 154.

14. Assis, C. P. O.; Gondim-Jr, M. G. C.; de Siqueira, H. A. A.; da Camara, C. A. G.; J. Stored Prod. Res. 2011, 47, 311.

15. Tia, V. E.; Lozano, P.; Menut, C.; Lozano, Y.; Martin, T.; Niamké, S.; Adima, A. A.; Phytotherapie 2013, 11, 31.

16. Amer, A.; Mehlhorn, H.; Parasitol. Res. 2006, 99, 478.

17. Van den dool, H.; Kratz, P. D.; J. Chromatogr. A 1963, 11, 463.

18. Adams, R. P.; Identification of Essential Oil Components by Gas Chromatography/Quadrupole Mass Spectroscopy, $4^{\text {th }}$ ed.; Allured Publ. Corp: Carol Stream, 2007.

19. Ribeiro, N.; Camara, C. A. G.; Ramos C. S.; Chil. J. Agric. Res. 2016, 76, 71.

20. Bandeira, G. N.; da Camara, C. A. G.; de Moraes, M. M.; Barros, R.; Muhammad, S.; Akhtar, Y.; J. King Saud Univ., Sci. 2013, $25,83$.

21. Moraes, M. M.; da Camara, C. A. D.; Silva, M.; An. Acad. Bras. Cienc. 2017, 89, 1417

22. Salman, S. Y.; Saritas, S.; Kara, N.; Aydinli, F.; Ay, R.; J. Essent. Oil-Bear. Plants 2015, 18, 857.

23. Zago, H. B.; Barros, R.; Torres, J. B.; Pratissoli, D.; Neotrop. Entomol. 2010, 39, 241.

24. Finney, D. J.; Probit Analysis, $3^{\text {rd }}$ ed.; University Press: Cambridge, 1971.

25. SAS software, version 9.0; SAS Institute Inc., Cary, USA, 2002.

26. Adjalian, E.; Sessou, P.; Yehouenou, B.; Fifa, T. D. B.; Noudogbessi, J. P.; Kossou, D.; Menut, C.; Sohounhloue, D.; Int. J. Biol., Pharm. Allied Sci. 2015, 4, 797.

27. Colmenares, N. G.; Rodríguez, G. O.; Prieto, A.; Crescente, O.; Cabrera, L.; Ciencia 1998, 6, 123.

28. Pujiarti, R.; Ohtani, Y.; Ichiura, H.; J. Wood Sci. 2012, 58, 429.
29. Pujiarti, R.; Ohtani, Y.; Ichiura, H.; J. Wood Sci. 2011, 57, 446.

30. Muchtaridi, M.; Tjiraresmi, A.; Febriyanti, R.; Indones. J. Pharm. 2015, 26, 219.

31. Farag, R. S.; Shalaby, A. S.; El-Baroty, G. A.; Ibrahim, N. A.; Ali, M. A.; Hassan, E. M.; Phytother. Res. 2004, 18, 30.

32. Kumar, A.; Tandon, S.; Yadav, A.; J. Essent. Oil-Bear. Plants 2005, 8, 19.

33. Pino, J.; Bello, A.; Urquiola, A.; Aguero, J.; Marbot, R.; J. Essent. Oil Res. 2002, 14, 10.

34. Todorova, M.; Ognyanov, I.; The, P. T. T.; Perfum. Flavor. 1988, $13,17$.

35. Manurung, R.; Widiana, A.; Taufikurahman, Limin, S. H.; Adv. Nat. Appl. Sci. 2015, 9, 39.

36. Zhang, J.; Wu, H.; Jiang, D.; Yang, Y.; Tang, W.; Xu, K.; Nat. Prod. Res. 2018, 14, 2545.

37. Siddique, S.; Parveen, Z.; Firdaus-e-Bareen; Mazhar, S.; Arabian J. Chem. 2017, DOI: 10.1016/j.arabjc.2017.01.018.

38. Khan, M.; Khan, S. T.; Khan, N. A.; Mahmood, A.; Al-Kedhairy, A. A.; Alkhathlan, H. Z.; Arabian J. Chem. 2018, 11, 1189.

39. da Camara, C. A.; de Moraes, M. M.; de Melo, J. P.; da Silva, M. M. C.; J. Essent. Oil-Bear. Plants 2017, 20, 1434.

40. Sangha, J. S.; Astatkie, T.; Cutler, G. C.; Can. Entomol. 2017, 149, 639 .

41. Moraes, M. M.; da Camara, C. A. G.; dos Santos, M. L.; Fagg, C. W.; J. Braz. Chem. Soc. 2012, 23, 1647.

42. Verkerk, R. H. J.; Wright, D. J.; Pestic. Sci. 1993, 37, 83.

43. Arthropod Pesticide Resistence Database (APRD), available at http://www.pesticideresistance.org/display. php? page $=$ species $\&$ arId $=536$, accessed in October 2019.

44. Ferreira, C. B. S.; Andrade, F. H. N.; Rodrigues, A. R. S.; Siqueira, H. A. A.; Gondim-Jr, M. G. C.; Crop Prot. 2015, 67, 77.

45. Feng, R.; Isman, M. B.; Experientia 1995, 8, 831.

46. Koul, O.; Walia, S.; CAB Rev. 2009, 49, 1.

Submitted: July 1, 2019

Published online: October 15, 2019 